\title{
Intensive care medicine rapid practice guidelines (ICM-RPG): paving the road of the future
}

Waleed Alhazzani ${ }^{1,2^{*}} \mathbb{0}$, Morten Hylander Møller ${ }^{3,4}$, Emilie Belley-Cote ${ }^{1,2}$ and Giuseppe Citerio ${ }^{5}$

(C) 2019 Springer-Verlag GmbH Germany, part of Springer Nature

Over the past decade, clinical practice guidelines (CPGs) have undergone extensive and rapid development. The credibility of CPGs is proportional to the methodological rigour, effective management of conflict of interest (COI), incorporation of patients' values and preferences, and transparency of judgments. With the emergence of the Grading of recommendations, assessment, development and evaluation (GRADE) approach, CPG development has become systematic, transparent, and based on explicit judgments. The GRADE approach is an essential component of trustworthy CPGs. GRADE has been adopted by more than 100 organisations worldwide, including the Cochrane Collaboration, the World Health Organization, UpToDate, and many professional societies within critical care [1]. Intensive care medicine (ICM) now joins this list. Here, we provide an introduction and overview of the new series in ICM rapid practice guidelines (ICM-RPGs).

Most CPGs, including in the field of critical care, are at best updated every 3-5 years [2]. Between updates, new and potentially practice-changing evidence may emerge, but guidelines will not incorporate it until their next iteration, potentially delaying evidence dissemination and implementation in clinical practice. Outdated recommendations may also undermine CPGs' credibility. It is a priority to speed the integration of new evidence in guidelines.

With the ICM-RPGs, we aim to ensure timely production of trustworthy clinical practice recommendations on topical questions related to critical illness diagnosis and/

\footnotetext{
*Correspondence: alhazzaw@mcmaster.ca

${ }^{1}$ Department of Medicine, McMaster University, Hamilton, Canada

Full author information is available at the end of the article
}

or management. The ICM-RPGs are intended for clinicians and other healthcare professionals caring for critically ill patients.

The process for developing ICM-RPGs is summarised as follows:

Academic critical care clinicians and methodologists experienced in CPG development from the ICM-RPG steering committee (Fig. 1). This committee receives alerts when new randomised clinical trials (RCTs) and systematic reviews in the field are published. When a study may impact clinical practice, i.e. may change practice or introduce equipoise, the steering committee will propose a new ICM-RPG to the ICM editorial board. After ICM-RPG approval, the steering committee will gather a panel, aiming for appropriate gender and geographic balance; the panel will be comprised of key stakeholders including experienced methodologists, academic clinicians, content experts (i.e. leading researcher(s) on this topic), frontline clinicians, allied health professionals, and patient representative(s). The steering committee will also assign a Clinical Chair and a Methods Chair, both of which should not have financial or academic conflicts of interest. Methodologists and statisticians from the Guidelines in intensive care development and evaluation (GUIDE) group will support the panel. Panel members' disclosed conflicts of interest will be adjudicated and managed as previously outlined [3,4]. The panel will formulate the specific components of the guideline question(s), including the population, interventions, and outcomes in the PICO format [5]. When appropriate, an independent systematic review team from GUIDE will conduct a rapid systematic review and meta-analysis [6], with input from the panel and the methods team. The methods team, in collaboration with the panel, will assess

\section{Springer}




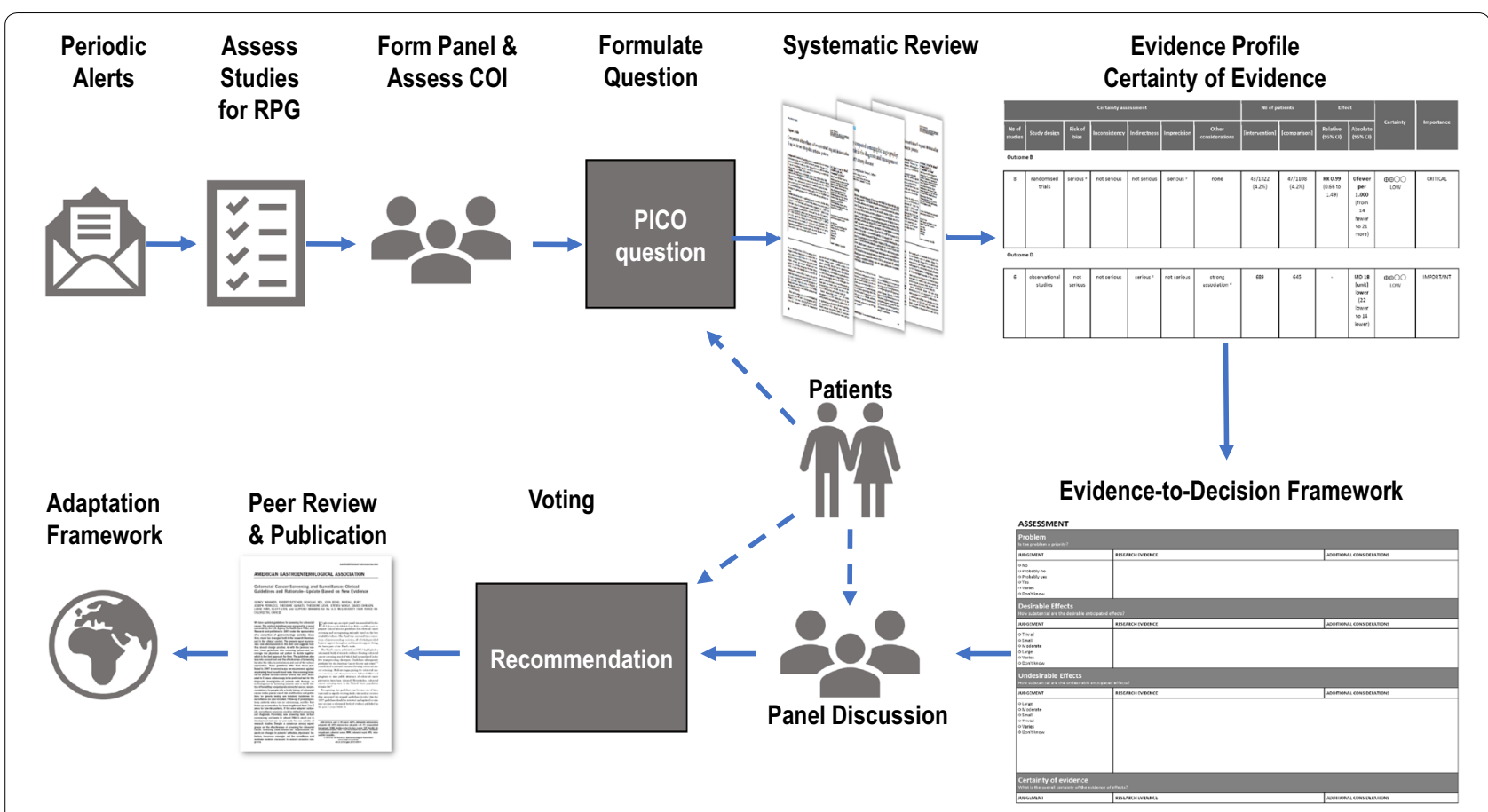

Fig. 1 This figure summarises the ICM-RPG development process

the certainty of evidence (also referred to as the quality of evidence or the confidence in the effect estimates) using the GRADE approach [7]. In brief, the certainty of evidence will be categorised as very low, low, moderate or high based on risk of bias, imprecision, indirectness, inconsistency, and publication bias [8]. In general, RCTs start as high certainty evidence, while observational studies start as low certainty evidence [7]. We will present transparent and explicit ratings of the certainty of evidence for each outcome in an evidence profile table with the judgements for each GRADE domain and the relative and absolute effects for each outcome [9].

To ensure maximal guideline relevance in clinical practice, the ICM-RPG panel will aim to issue a recommendation whenever possible. Recommendations will be presented as either strong (phrased as "we recommend") or conditional (also known as weak and phrased as "we suggest"). The strength of recommendation will depend on the certainty of evidence across all outcomes, the balance of benefits and harms, patients' values and preferences, cost and resource utilisation, feasibility, and acceptability. In the recommendation formulation phase, we will use the Evidence-to-Decision framework to evaluate these factors [10].

When appropriate, visual decision aids will accompany published ICM-RPGs to facilitate guideline implementation. In addition, the panel will provide suggestions to implement the ICM-RPGs in various contexts (e.g. low-middle-income countries/high-income countries) using existing adaptation frameworks [11].

ICM is the sponsoring organisation and is responsible for forming and overseeing the ICM-CPR steering committee. The GUIDE Group will support methodological and statistical aspects of the ICM-RPG development. All ICM-RPGs will undergo peer and editorial review through ICM.

The British Medical Journal Rapid Recommendation Group developed a similar process and successfully generated several recommendations on different topics in medicine [12]. They have demonstrated the feasibility of conducting high-quality systematic reviews and trustworthy guidelines within a short period of time.

We hope the ICM-RPGs will hasten the translation of evidence in clinical practice. Stay tuned for the first ICM-RPG addressing the use of neuromuscular blocking agents in moderate-to-severe acute respiratory distress syndrome, planned publication in the near future.

\section{Abbreviations \\ CPG: Clinical practice guidelines; EtD: Evidence to decision; GUIDE: Guidelines in intensive care development and evaluation; GRADE: Grading of recom- mendations, assessment, development and evaluation; ICM: Intensive care medicine; RPG: Rapid practice guidelines.}

\section{Author details}

${ }^{1}$ Department of Medicine, McMaster University, Hamilton, Canada. ${ }^{2}$ Department of Health Research Methods, Evidence and Impact, McMaster University, Hamilton, Canada. ${ }^{3}$ Department of Intensive Care 4131, Copenhagen 
University Hospital, Rigshospitalet, Copenhagen, Denmark. ${ }^{4}$ Centre for Research in Intensive Care, Copenhagen, Denmark. ${ }^{5}$ School of Medicine and Surgery, University of Milan-Bicocca, Milan, Italy.

\section{Compliance with ethical standards}

\section{Conflicts of interest}

WA and EB is the chairs of the GUIDE Group that is supporting this initiative; MHM is a GUIDE Group member. GC has no conflicts related to this topic

\section{Publisher's Note}

Springer Nature remains neutral with regard to jurisdictional claims in published maps and institutional affiliations.

Received: 7 September 2019 Accepted: 10 September 2019

Published online: 24 September 2019

\section{References}

1. Qaseem A, Forland F, Macbeth F, Ollenschlager G, Phillips S, van der Wees P, Board of Trustees of the Guidelines International N (2012) Guidelines international network: toward international standards for clinical practice guidelines. Ann Intern Med 156:525-531

2. Rhodes A, Evans LE, Alhazzani W, Levy MM, Antonelli M, Ferrer R, Kumar A, Sevransky JE, Sprung CL, Nunnally ME, Rochwerg B, Rubenfeld GD, Angus DC, Annane D, Beale RJ, Bellinghan GJ, Bernard GR, Chiche JD, Coopersmith C, De Backer DP, French CJ, Fujishima S, Gerlach H, Hidalgo JL, Hollenberg SM, Jones AE, Karnad DR, Kleinpell RM, Koh Y, Lisboa TC, Machado FR, Marini JJ, Marshall JC, Mazuski JE, McIntyre LA, McLean AS, Mehta S, Moreno RP, Myburgh J, Navalesi P, Nishida O, Osborn TM, Perner A, Plunkett CM, Ranieri M, Schorr CA, Seckel MA, Seymour CW, Shieh L, Shukri KA, Simpson SQ, Singer M, Thompson BT, Townsend SR, Van der Poll T, Vincent JL, Wiersinga WJ, Zimmerman JL, Dellinger RP (2017) Surviving sepsis campaign: international guidelines for management of sepsis and septic shock: 2016. Intensive Care Med 43:304-377

3. Alhazzani W, Lewis K, Jaeschke R, Rochwerg B, Moller MH, Evans L, Wilson KC, Patel S, Coopersmith CM, Cecconi M, Guyatt G, AkI EA (2018) Conflicts of interest disclosure forms and management in critical care clinical practice guidelines. Intensive Care Med 44:1691-1698
4. Vandvik PO, Alhazzani W, Moller MH (2018) Understanding conflicts of interest. Intensive Care Med 44:1738-1740

5. Guyatt GH, Oxman AD, Kunz R, Atkins D, Brozek J, Vist G, Alderson P, Glasziou P, Falck-Ytter Y, Schunemann HJ (2011) GRADE guidelines: 2. Framing the question and deciding on important outcomes. J Clin Epidemiol 64:395-400

6. Schunemann HJ, Moja L (2015) Reviews: rapid! rapid! rapid!... and systematic. Syst Rev 4:4

7. Guyatt GH, Oxman AD, Vist GE, Kunz R, Falck-Ytter Y, Alonso-Coello P, Schunemann HJ, Group GW (2008) GRADE: an emerging consensus on rating quality of evidence and strength of recommendations. BMJ 336:924-926

8. Balshem $H$, Helfand $M$, Schunemann HJ, Oxman AD, Kunz R, Brozek J, Vist GE, Falck-Ytter Y, Meerpohl J, Norris S, Guyatt GH (2011) GRADE guidelines: 3. Rating the quality of evidence. J Clin Epidemiol 64:401-406

9. Guyatt G, Oxman AD, Akl EA, Kunz R, Vist G, Brozek J, Norris S, Falck-Ytter Y, Glasziou P, DeBeer H, Jaeschke R, Rind D, Meerpohl J, Dahm P, Schunemann HJ (2011) GRADE guidelines: 1. Introduction-GRADE evidence profiles and summary of findings tables. J Clin Epidemiol 64:383-394

10. Alonso-Coello P, Oxman AD, Moberg J, Brignardello-Petersen R, Akl EA, Davoli M, Treweek S, Mustafa RA, Vandvik PO, Meerpohl J, Guyatt GH, Schunemann HJ, Group GW (2016) GRADE evidence to decision (EtD) frameworks: a systematic and transparent approach to making well informed healthcare choices. 2: Clinical practice guidelines. BMJ 353:i2089

11. Schunemann HJ, Wiercioch W, Brozek J, Etxeandia-Ikobaltzeta I, Mustafa RA, Manja V, Brignardello-Petersen R, Neumann I, Falavigna M, Alhazzani W, Santesso N, Zhang Y, Meerpohl JJ, Morgan RL, Rochwerg B, Darzi A, Rojas MX, Carrasco-Labra A, Adi Y, AlRayees Z, Riva J, Bollig C, Moore A, Yepes-Nunez JJ, Cuello C, Waziry R, AkI EA (2017) GRADE evidence to decision (EtD) frameworks for adoption, adaptation, and de novo development of trustworthy recommendations: GRADE-ADOLOPMENT. J Clin Epidemiol 81:101-110

12. Vandvik PO, Otto CM, Siemieniuk RA, Bagur R, Guyatt GH, Lytvyn $L$, Whitlock R, Vartdal T, Brieger D, Aertgeerts B, Price S, Foroutan F, Shapiro M, Mertz R, Spencer FA (2016) Transcatheter or surgical aortic valve replacement for patients with severe, symptomatic, aortic stenosis at low to intermediate surgical risk: a clinical practice guideline. BMJ 354:15085 